\title{
pH-responsive cellulose-chitosan nanocomposite films with slow release of chitosan
}

\author{
Jiayi Yang • Christina Dahlström • Håkan Edlund • Björn Lindman • \\ Magnus Norgren 10
}

Received: 21 November 2018/ Accepted: 28 February 2019/Published online: 6 March 2019

(C) The Author(s) 2019

\begin{abstract}
Cellulose-chitosan films were prepared using a physical method in which cellulose and chitosan were separately dissolved via freeze thawing in $\mathrm{LiOH} /$ urea and mixed in different proportions, the resulting films being cast and regenerated in water/ ethanol. X-ray diffraction and Fourier transform infrared spectroscopy (FT-IR) spectroscopy verified the composition changes in the nanocomposites due to different mixing ratios between the polymers. Tensile stress-strain measurements indicated that the mechanical performance of the cellulose-chitosan nanocomposites slightly worsened with increasing chitosan content compared with that of films comprising cellulose alone. Field emission scanning electron microscopy revealed the spontaneous formation of nanofibers in the films; these nanofibers were subsequently ordered into lamellar structures. Water uptake
\end{abstract}

and microscopy analysis of film thickness changes indicated that the swelling dramatically increased at lower $\mathrm{pH}$ and with increasing chitosan content, this being ascribed to the Gibbs-Donnan effect. Slow material loss appeared at acidic $\mathrm{pH}$, as indicated by a loss of weight, and quantitative FT-IR analysis confirmed that chitosan was the main component released. A sample containing $75 \%$ chitosan reached a maximum swelling ratio and weight loss of $1500 \%$ and $55 \mathrm{wt} \%$, respectively, after $12 \mathrm{~h}$ at $\mathrm{pH} 3$. The study presents a novel way of preparing $\mathrm{pH}$-responsive cellulose-chitosan nanocomposites with slow-release characteristics using an environmentally friendly procedure and without any chemical reactions.

J. Yang · C. Dahlström · H. Edlund · B. Lindman ·

M. Norgren $(\square)$

FSCN, Surface and Colloid Engineering, Mid Sweden

University, SE-85170 Sundsvall, Sweden

e-mail: magnus.norgren@miun.se 


\section{Graphical abstract}

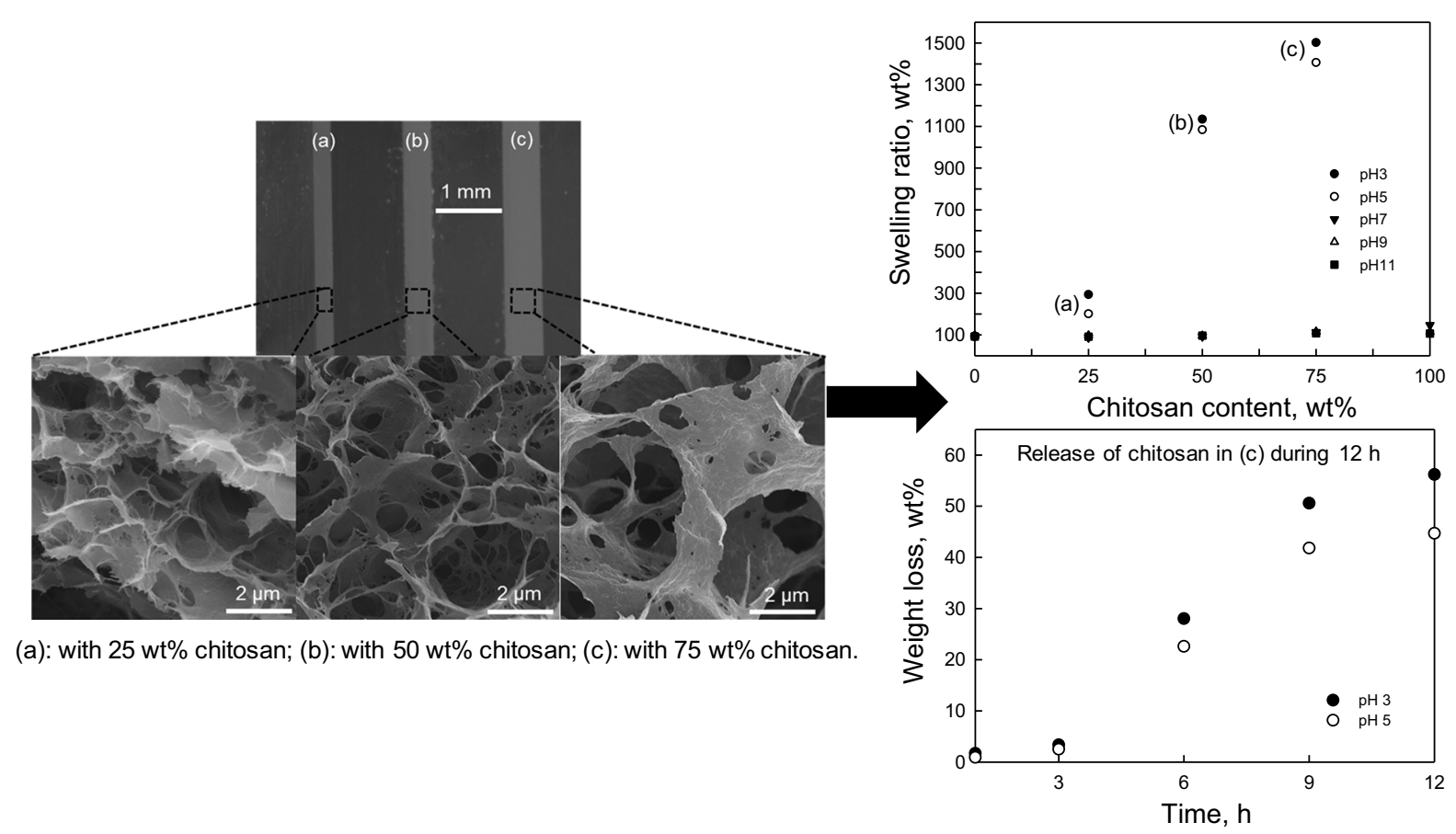

Keywords Cellulose dissolution - Chitosan dissolution $\cdot \mathrm{pH}$ responsive $\cdot$ Gibbs-Donnan equilibrium $\cdot$ Nanocomposite $\cdot$ Slow release

\section{Introduction}

Ecological awareness has driven the search for substituents and new materials derived from renewable resources using environmentally friendly processing routes. Cellulose and chitin, the most abundant biopolymers on Earth (Hadwiger 2013; Klemm et al. 2005), have attracted great attention for designing new materials and products due to their renewability, biodegradability, and low cost. Cellulose and chitin are polysaccharides that support organisms in the plant and animal kingdoms, respectively. Their chemistries are relatively similar, having $\beta-1,4$ bonds between repeating sugar units and complex networks of hydrogen bonding and hydrophobic interactions maintaining the polymer chain structures (Medronho and Lindman 2014; Yang et al. 2016).

Cellulose and chitosan (easily derived from chitin), biopolymers known since the 19th century, both play substantial roles in various composite applications, such as textiles and packaging (Qiu and Hu 2013), waste water purification (Zargar et al. 2015), tissue engineering (Sowjanya et al. 2013), wound healing (Xiao et al. 2013), and other biomedical applications (Kim et al. 2011; Szymanska and Winnicka 2015). Besides cellulose and chitosan composites, efforts have also been made to form functionalized composite materials, such as chitosan-cellulose nanofibers (Fernandes et al. 2011), chitosan-cellulose nanowhiskers (Li et al. 2009), and chitosan-cellulose multi-component composites (Tang and Alavi 2011). These composite materials can be given anti-microbial or wound-healing properties, $\mathrm{pH}$ sensitivity, or other functionalities. In some cases, metallic nanoparticles or other components are applied to achieve the desired functionality ( $\mathrm{Li}$ et al. 2010). Having cellulose and chitosan in a common solvent would greatly facilitate the manufacture of such composites. A common method for preparing cellulose-chitosan composites is mixing derivatized polymers in common solvents. The derivatization of either cellulose or chitosan would render polymers with different properties, but may lower the biocompatibility of the composite, increasing both environmental concerns and 
processing complexity. Hence, dissolving and preparing cellulose-chitosan composites in a compatible solvent without previous derivatization would be advantageous.

Various solvents have been investigated for dissolving cellulose and chitosan, solvents such as ionic liquids, acidic solvents, and alkaline solvents. Using ionic liquids to directly dissolve cellulose has been studied since 2002 (Swatloski et al. 2002), revealing that ionic liquids can dissolve chitosan and other polysaccharides (Kuzmina et al. 2012). However, the mechanism behind the dissolution of polysaccharides is not well understood. Apparently, the dissolution is mainly governed by the interaction between the anions and the polysaccharide molecules, yet the particular combinations of cations and anions significantly affect the dissolution power of the ionic liquids (Pinkert et al. 2009). As well as deficient knowledge of the dissolution mechanism, their high viscosity, high production cost, moisture sensitivity, and poorly developed purification processes have made it difficult to use ionic liquids at industrial scale (Alexandridis et al. 2018; Li et al. 2018).

Regarding water-based systems, acidic solvents are generally more efficient than alkaline ones. However, in acidic cellulose dissolution, hydrolysis of the $\beta-1,4$ glycosidic bonds in the polymer chain occurs over time, reducing molecular mass, promoting dissolution, and yielding regenerated material with inferior properties. Protonation of the hydroxyl groups via the fast diffusion of protons in acidic solvents contributes to the fast dissolution of cellulose. Both the amorphous and crystalline regions of cellulose are quickly disassembled and can be easily protonated (Lindman et al. 2010; Zhang et al. 2006). Unlike cellulose, chitosan is readily soluble even in weakly acidic solvents because the primary amine group in chitosan has a $\mathrm{pK}_{\mathrm{a}}$ value of 6.5. Therefore, at a lower $\mathrm{pH}$, the amine groups are protonated and positively charged, making chitosan a cationic polyelectrolyte (Zargar et al. 2015). The electrostatic repulsion between the molecular chains in terms of the counterion entropy thus favors the dissolution of chitosan in acidic solvents (Szymanska and Winnicka 2015). As discussed above, dissolution in strongly acidic media is typically accompanied by the chemical degradation of cellulose and chitosan, which can jeopardize the properties of the regenerated products (Liebert 2010; Nguyen et al. 2008).
Regarding the use of aqueous alkaline solvents to dissolve cellulose or chitosan, recent developments have concerned use of different additives and freezethawing at $-12{ }^{\circ} \mathrm{C}$ or lower (Cai and Zhang 2005; Zhang and Xia 2014). Some hydroxyl groups are deprotonated at extreme $\mathrm{pH}$ (Alves et al. 2016; Bialik et al. 2016), and the polymer networks become highly swollen (Isogai 1997; Lindman et al. 2017; Saric and Schofield 1946). Additionally, some authors argue that ice expansion at lower temperatures further opens up the structure (Cai and Zhang 2005; Zhang and Xia 2014), and that more favorable water-polymer interactions also play a role (Lindman et al. 2010). The hypothesis that cellulose is an amphiphilic polymer has received increased acceptance (Glasser et al. 2012; Lindman et al. 2010). This explains why, to better dissolve cellulose or chitosan in alkaline solutions, it is helpful to have additives, such as urea or thiourea, that decrease the hydrophobic interactions (Cousins and Brown 1995; Lindman et al. 2010; Medronho and Lindman 2014).

Whereas different approaches have been developed over the years to dissolve cellulose and chitosan in the same solvent to create a composite, most of the approaches are inappropriate for industrial production or unacceptable due to increasing environmental concerns (Liebert 2010; Niroomand et al. 2016). However, cellulose or chitosan dissolution in a nontoxic, low-cost, and environmentally friendly aqueous solvent merits further investigation, particularly in relation to the preparation and design of nanocomposites with properties tunable for specific applications and functions. One notable functionality of cellulose-chitosan nanocomposites is $\mathrm{pH}$ responsiveness, which gives these nanocomposites $\mathrm{pH}$-dependent swelling properties (Duan et al. 2017; Omidi et al. 2017). The nanocomposite $\mathrm{pH}$ response is driven by the Gibbs-Donnan equilibrium, based on the difference in osmotic pressure caused by the difference in counterion concentration between the inner gel phase and the outer solution (Grignon and Scallan 1980). This responsive behavior is a key feature of advanced artificial materials and devices widely used in the medical, pharmaceutical, and agricultural fields (Sidorenko et al. 2007).

In this study, $\mathrm{pH}$-responsive cellulose-chitosan nanocomposite films with slow release of chitosan were prepared and characterized. The $\mathrm{pH}$ responsiveness is an important feature for various applications, 
especially wound dressing, in which various $\mathrm{pH}-$ responsive materials are applied as a simple method to monitor $\mathrm{pH}$ during healing (Srinivasan and Mahadevan 2010). In addition to $\mathrm{pH}$ responsiveness, the slow release of chitosan makes the nanocomposite both a wound dressing candidate and a drug delivery system for carrying active substances that promote wound healing (Liu et al. 2018). Cellulose and chitosan are adequate candidates for preparing nanocomposite films with $\mathrm{pH}$ responsiveness because both renewable polymers are biocompatible and biodegradable. Additionally, the osmotic pressure change that occurs with the protonation of the primary amine groups in chitosan suggests that a cellulose-chitosan nanocomposite would respond well to changes in $\mathrm{pH}$, indicating the potential for tuning the $\mathrm{pH}$ response of the composite material. The objectives of this work were accordingly to prepare cellulose-chitosan nanocomposite films at different polymer mixing ratios and to investigate their chemical and mechanical properties and $\mathrm{pH}-$ responsive functionality.

\section{Materials and methods}

\section{Chemicals and reagents}

The cellulose used was a commercial-sulfite-dissolved pulp with a weight average molecular weight $\left(M_{w}\right)$ of $3.2 \times 10^{5} \mathrm{~g} \mathrm{~mol}^{-1}$ and a polydispersity index of 10.3, provided by Domsjö Fabriker Aditya Birla
(Örnsköldsvik, Sweden). Commercial grade chitosan from shrimp shells with weight average molecular weight $\left(M_{w}\right)$ of $3.6 \times 10^{5} \mathrm{~g} \mathrm{~mol}^{-1}$ and degree of deacetylation of $89 \%$, was supplied by Regal Biology Ltd. (Shanghai, China) (Duan et al. 2015). The other chemicals, i.e., lithium hydroxide $(\mathrm{LiOH})$, potassium hydroxide $(\mathrm{KOH})$, urea, and ethanol, were of analytical grade and supplied by VWR Prolabo Chemicals (Stockholm, Sweden).

\section{Dissolution of cellulose and chitosan}

The cellulose and chitosan dissolution was achieved in different aqueous solvents. For cellulose, an aqueous solvent comprising LiOH/urea/water (4.6:15:80.4 w/ w) was prepared and frozen for the dissolution. Then, $4 \mathrm{~g}$ of cellulose was dispersed with extensive stirring in $96 \mathrm{~g}$ of thawed LiOH/urea solvent. For chitosan, $4 \mathrm{~g}$ of chitosan was dispersed and frozen in $96 \mathrm{~g}$ of a $\mathrm{LiOH} / \mathrm{KOH} /$ urea/water solvent (4.6:7:8:80.4 w/w). $\mathrm{KOH}$ was used to promote the dissolution of chitosan (Fang et al. 2017). Both the cellulose and chitosan solutions were then kept at $-35^{\circ} \mathrm{C}$ until completely frozen. Next, the solutions were thawed at room temperature and stirred at $1300 \mathrm{rpm}$ for $2 \mathrm{~min}$. The freezing-thawing-stirring cycle was repeated twice more until the cellulose and chitosan were fully dissolved. A $4 \mathrm{wt} \%$ transparent cellulose-chitosan solution was obtained after the air bubbles were removed by centrifuging the sample at $8000 \mathrm{rpm}$ and $0{ }^{\circ} \mathrm{C}$ for 10 min (Beckman Culter, Avanti J-25 with

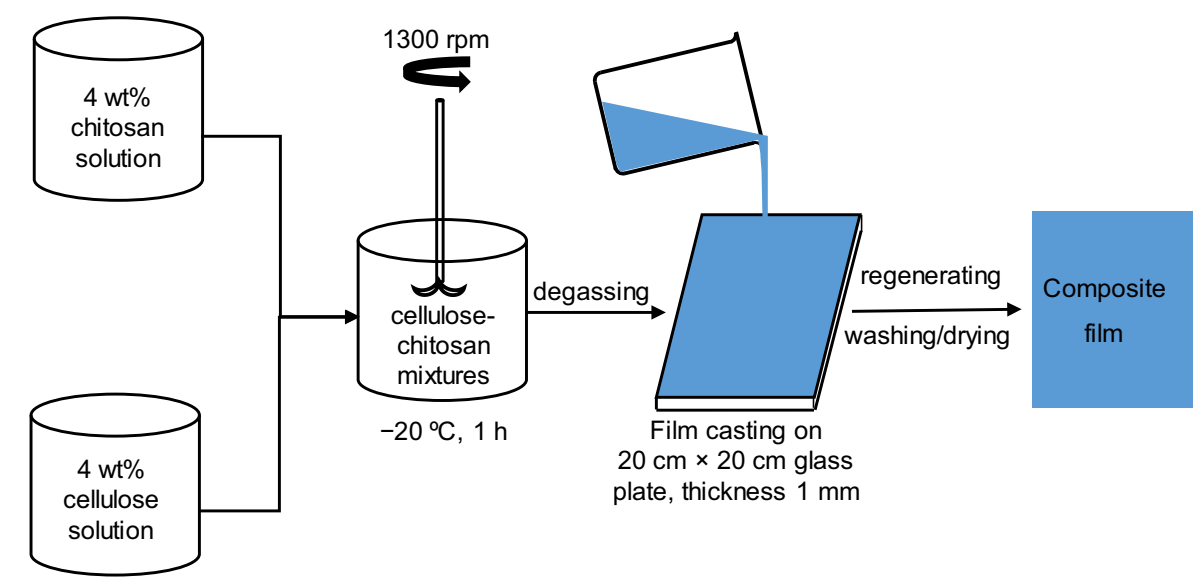

Scheme 1 Route for preparing cellulose-chitosan nanocomposite films. Aqueous alkaline solutions of cellulose and chitosan were mixed in different ratios, and the mixtures were degassed, cast, and regenerated in water/ethanol. After washing in water and drying at $95{ }^{\circ} \mathrm{C}$ in Rapid Köthen for 10 min under vacuum, the films were characterized and tested 
JLA-16.250 Fixed Angle Rotor, Indianapolis, United States).

Preparation of cellulose-chitosan composite films

Pure cellulose and chitosan reference films were prepared by directly casting the stock solutions on $20 \mathrm{~cm} \times 20 \mathrm{~cm}$ glass plate with a thickness of $1 \mathrm{~mm}$. Then, the glass plates with the cast solutions were then carefully immersed in a water/ethanol bath for regeneration. A solution mixture ratio of 4:6 water/ethanol was found to give films with low stickiness and film shrinkage. The cellulose-chitosan nanocomposite films with different cellulose/chitosan ratios were prepared as illustrated in Scheme 1. The stock solutions of cellulose and chitosan were premixed at different weight ratios before the casting and regeneration. The films were dried in Rapid Köthen (PTI, Laakirchen, Austria) at $95{ }^{\circ} \mathrm{C}$ under vacuum for $10 \mathrm{~min}$. The nanocomposite films were prepared with different chitosan contents: $25 \%$ chitosan and $75 \%$ cellulose (C25), 50\% chitosan and $50 \%$ cellulose (C50), and $75 \%$ chitosan and $25 \%$ cellulose (C75).

Physical and chemical characterizations

The morphologies of the prepared films were characterized using field emission scanning electron microscopy (FE-SEM) (TESCAN MAIA3 SEM; Oxford Instruments, Abingdon, UK) at an accelerating voltage of $15 \mathrm{kV}$; the films were given a 5 -nm iridium coating using a turbomolecular pumped coater (Q150 T ES;
Quorum Technologies, Lewes, UK). The surface structures of the films were further characterized using a Fourier transform infrared spectroscope (Nicolet 6700; Thermo Scientific, Waltham, MA, USA) in attenuated total reflectance mode, and all samples were examined using a $4 \mathrm{~cm}^{-1}$ resolution and 64 scans in the range of $400-4000 \mathrm{~cm}^{-1}$. The diffraction patterns of the prepared films were obtained using an X-ray diffractometer (XRD) instrument (D Phaser; Bruker, Billerica, MA, USA) with $\mathrm{Cu} \mathrm{K} \alpha$ radiation of $1.54 \AA$ at $30 \mathrm{kV}$ and $10 \mathrm{~mA}$, and the patterns were recorded in the $2 \theta$ region from $5^{\circ}$ to $45^{\circ}$ at a scanning rate of $0.01^{\circ} \mathrm{s}^{-1}$. The mechanical properties were determined using a universal material testing machine equipped with a $100 \mathrm{~N}$ load cell (MTS Systems, Eden Prairie, MN, USA). Five $50 \times 5$-mm specimens were tested at a cross-head speed of $1.5 \mathrm{~mm} \mathrm{~min}^{-1}$. The film thickness before and after swelling was measured using a micrometer (Uninor, Stockholm, Sweden) with a precision of $1 \mu \mathrm{m}$, and the thickness after swelling was monitored using a light microscope (Observer Z1; Carl Zeiss, Oberkochen, Germany). The density of film was calculated as:

$\rho=\frac{W_{1}}{L \times D \times t}$

where $W_{1}, L, D$, and $t$ are the weight, length, width, and thickness of the dry film, respectively. Three $10 \times 10$ $\mathrm{mm}$ specimens were used to gravimetrically investigate the swelling in aqueous solutions at different $\mathrm{pHs}$. The swelling ratio (SR) was calculated as:
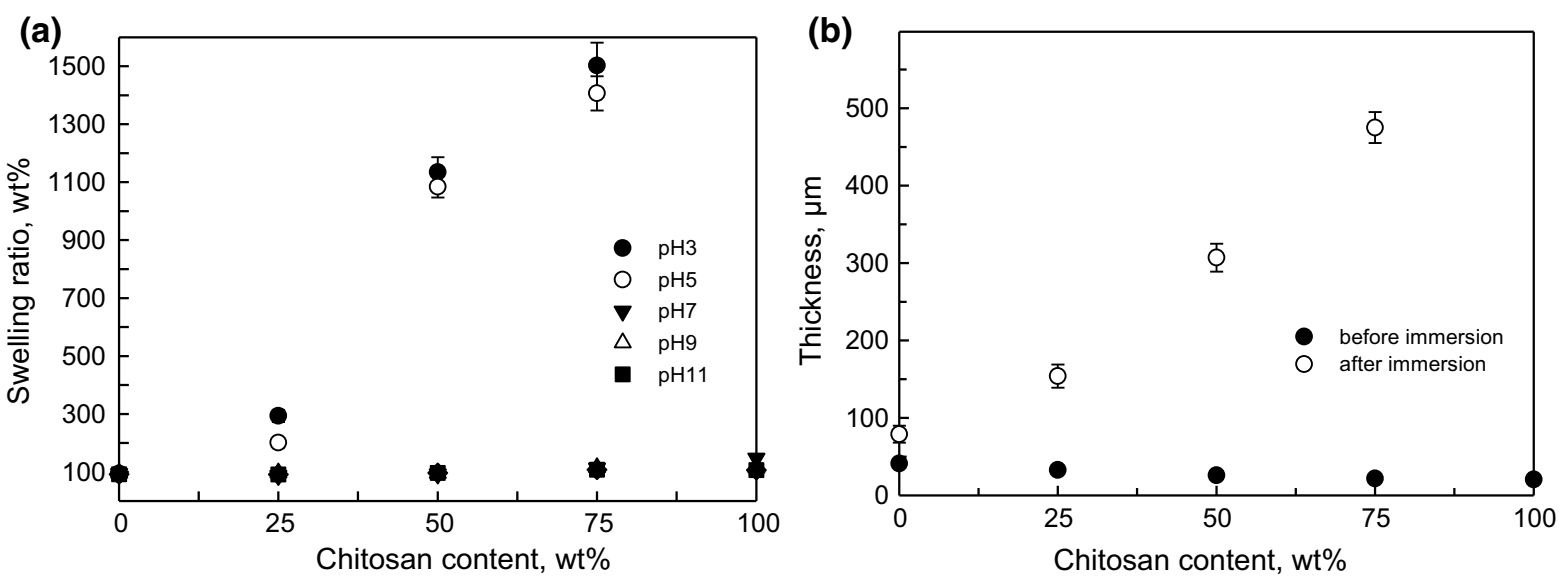

Fig. 1 Swelling ratios (a) of the films after immersing in water at pH 3, 5, 7, 9 and 11 for $12 \mathrm{~h}$; observed thicknesses (b) of the films before immersion and after immersion at $\mathrm{pH} 3$ for $12 \mathrm{~h}$. The $100 \mathrm{wt} \%$ chitosan films at $\mathrm{pH} 3$ and 5 were dissolved after $12 \mathrm{~h}$ 
$S R=\frac{W_{2}-W_{1}}{W_{1}} \times 100 \%$

where $W_{1}$ is the weight of the dry film and $W_{2}$ is the weight of the swollen film. A $1 \%$ acetic acid and a $0.1 \mathrm{M} \mathrm{NaOH}$ solution were used to adjust the $\mathrm{pH}$. The samples' weight losses before and after swelling at $\mathrm{pH}$ 3, 5 and 7 were also compared. The swollen samples were dried at $105{ }^{\circ} \mathrm{C}$ for $2 \mathrm{~h}$, and the weight loss was calculated as:

Weight loss $=\frac{W_{1}-W_{3}}{W_{1}} \times 100 \%$

where $W_{1}$ and $W_{3}$ are the weights of the dried film before and after the swelling test, respectively.

\section{Results and discussion}

Film swelling and porosity

The effect of the cellulose-chitosan mixing ratios on the $\mathrm{pH}$ response of the cellulose-chitosan nanocomposite films was investigated. The nanocomposite samples were immersed in aqueous solutions at $\mathrm{pH} 3$, $5,7,9$, and 11 at $25^{\circ} \mathrm{C}$ for $6,12,24,48$, and $72 \mathrm{~h}$, respectively. The weights and thicknesses of the samples were recorded after they were removed from the solution and carefully wiped to remove the surface water. In the swelling test the weight of the swollen samples have reached equilibrium after $12 \mathrm{~h}$, and prolong the immersing time did not further increase the weight of the swollen films. The values within the interval of the first $12 \mathrm{~h}$ were thus reported. As illustrated in Fig. 1a, b, the samples with different cellulose-chitosan mixing ratios displayed very different responses over the investigated $\mathrm{pH}$ range. The samples containing chitosan displayed excellent responses at $\mathrm{pH} 3$ and 5, and they reached maximum swelling at $\mathrm{pH} 3$. These responses are attributable to the difference in osmotic pressure between the gel phase of the composite film and the solution phase caused by the protonation of chitosan, giving a difference in counterion concentration described by the Gibbs-Donnan membrane equilibrium (Bolton et al. 2011). When immersing the nanocomposite films in water at a $\mathrm{pH}$ below 6.5 , the protonation of the amine groups in chitosan became significant (Wang et al. 2006). The charges of the protonated chitosan inside the gel phase was neutralized by counterions exerting an osmotic pressure, causing changes in the $\mathrm{pH}$ response, for example, increases in the thicknesses and weights of the different nanocomposite films. This is why swelling ratios and thicknesses increased when

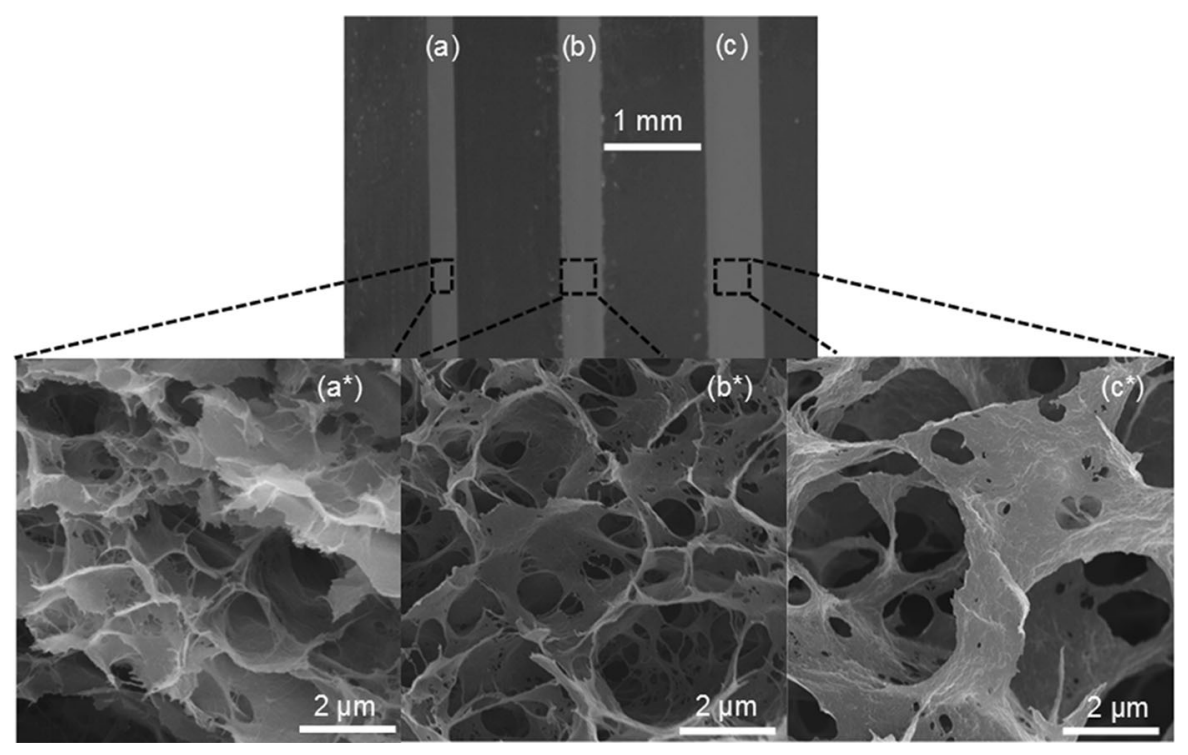

Fig. 2 Light microscope and SEM images of swollen cellulose-chitosan nanocomposite samples at $\mathrm{pH} 3$ after $12 \mathrm{~h}$ : (a) and $\left(\mathbf{a}^{*}\right) \mathrm{C} 25$, with $75 \mathrm{wt} \%$ cellulose and $25 \mathrm{wt} \%$ chitosan; (b) and (b*) C50, with $50 \mathrm{wt} \%$ cellulose and $50 \mathrm{wt} \%$ chitosan; (c) and (c*) C75, with 25 wt $\%$ cellulose and 75 wt $\%$ chitosan. C75, which has the highest chitosan content, swells the most, and displays the largest pores in its structure 
increasing the chitosan content of the nanocomposites. As the amount of chitosan in the nanocomposite increased from 0 to $75 \mathrm{wt} \%$, the nanocomposite sample reached maximum swelling at $\mathrm{pH} 3$, with the swelling ratios and thickness of $\mathrm{C} 75$ increasing nearly $1500 \mathrm{wt} \%$ and 22 times, respectively. The film of $100 \mathrm{wt} \%$ chitosan dissolved at $\mathrm{pH} 3$ and 5 after $12 \mathrm{~h}$. The $100 \mathrm{wt} \%$ cellulose film displayed limited and comparatively low swelling within the tested $\mathrm{pH}$ range. Because the deprotonation or protonation of hydroxyl groups in cellulose requires either an extremely high or an extremely low $\mathrm{pH}$, most of the swelling is attributed to the ionization of a small number of carboxylic acid groups as well as to capillary water uptake by the pores in the film. The films of $\mathrm{C} 75$ and of pure chitosan displayed slightly higher swelling at $\mathrm{pH} 7$ than at $\mathrm{pH} 9$ and 11, due to the partially protonated chitosan at the neutral $\mathrm{pH}$. The response at $\mathrm{pH} 9$ and 11 for the films was similar to that of the $100 \mathrm{wt} \%$ cellulose film and was constant. This result clearly indicated that without the protonation of the amine groups in the chitosan, the filmwater interactions were weak and only a limited $\mathrm{pH}$ response was observed. The moderate swelling of the composite films at high $\mathrm{pHs}$ was likely induced by the ionization of carboxylic acid groups and by the association between water molecules and the hydroxyl groups in the cellulose and chitosan polymer chains.

To further illustrate the structural changes in the cellulose-chitosan nanocomposites after swelling at different $\mathrm{pH}$ values, the swollen samples were analyzed using light microscopy and FE-SEM. Figure $2 \mathrm{a}-\mathrm{c}$ show that the nanocomposite samples responded very differently at $\mathrm{pH} 3$ depending on their chitosan content. The thicknesses before and after

Table 1 Weight losses of the samples after $12 \mathrm{~h}$ at $\mathrm{pH} \mathrm{3,5}$ and 7

\begin{tabular}{llll}
\hline Sample & \multicolumn{2}{l}{ Weight loss, wt\% } \\
\cline { 2 - 4 } & pH 3 & pH 5 & pH 7 \\
\hline Cellulose & 0 & 0 & 0 \\
C25 & $4.0 \pm 1.0$ & $2.8 \pm 1.1$ & $1.2 \pm 0.5$ \\
C50 & $27.0 \pm 2.6$ & $18.4 \pm 1.9$ & $2.5 \pm 0.9$ \\
C75 & $55.1 \pm 2.1$ & $45.7 \pm 3.6$ & $6.1 \pm 1.1$ \\
Chitosan & $-{ }^{\mathrm{a}}$ & - & $10.2 \pm 0.8$ \\
\hline
\end{tabular}

\footnotetext{
${ }^{\mathrm{a}}$ The chitosan sample dissolved after $12 \mathrm{~h}$
}

swelling, given in Fig. 1, also indicate that the chitosan content significantly influenced the swelling. The thickness of C75, the most swollen nanocomposite film, was $475 \mu \mathrm{m}$, more than three times the thickness of the swollen C25 film $(154 \mu \mathrm{m})$ and approximately 22 times that of the film before the test. This result directly proves that tuning the chitosan content resulted in different $\mathrm{pH}$ responses in the nanocomposite films. The FE-SEM micrographs of the films after water exposure, i.e., Fig. $2 \mathrm{a}^{*}-\mathrm{c}^{*}$, clearly show an increase in pore size in the microstructures, correlated with the $\mathrm{pH}$ response, as the chitosan content increased in the nanocomposite film. C75 clearly has larger pores than the other samples. The increased pore size was related to the protonation of chitosan and a greater osmotic pressure, but the acidic $\mathrm{pH}$ also favored dissolution of chitosan. It is therefore important to investigate the chitosan release of the swollen samples at acidic $\mathrm{pH}$.

Chitosan release: weight loss and FT-IR characterization

Chitosan has a pKa value of 6.5 , so the changes in its protonation state over the tested $\mathrm{pH}$ range are relevant for applications of the composite films. Protonation has two consequences, increased solubility and osmotic swelling, both caused by the entropy of the mobile counterions. Cellulose, in contrast, is only ionized at extreme $\mathrm{pH}$ values and thus is uncharged and insoluble under relevant application conditions.

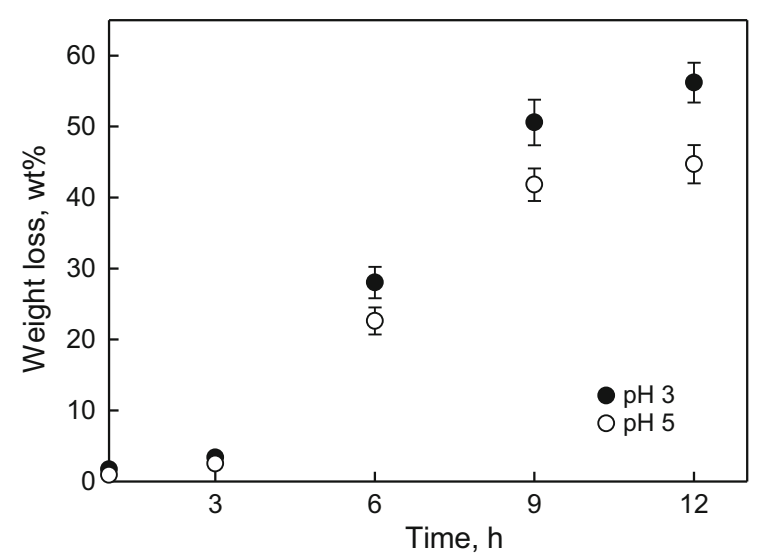

Fig. 3 Time dependence of the weight loss for films with 75 wt $\%$ chitosan at $\mathrm{pH} 3$ and 5 
(a)

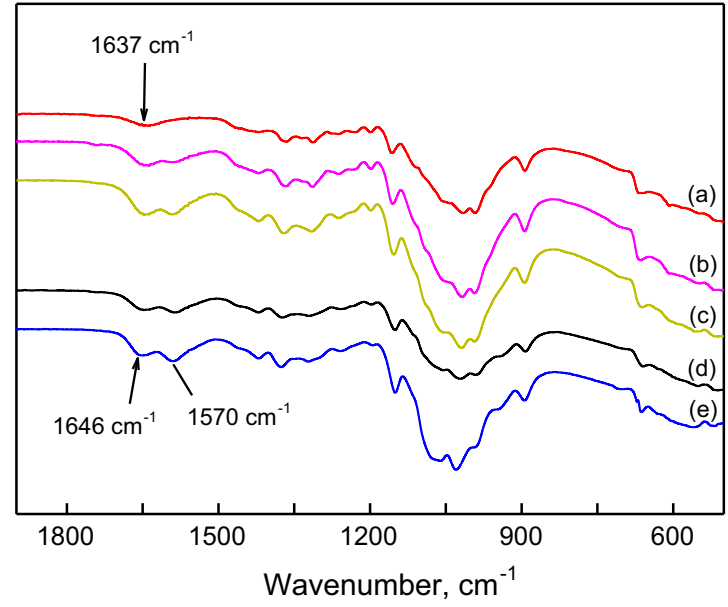

Fig. 4 FT-IR spectra of the films (A) and observed linear regression between the absorption peak intensity of amide II and the chitosan content (B). Samples in (A): (a) $100 \mathrm{wt} \%$ regenerated cellulose; (b) $\mathrm{C} 25$, with $75 \mathrm{wt} \%$ cellulose and $25 \mathrm{wt} \%$ chitosan; (c) C50, with $50 \mathrm{wt} \%$ cellulose and $50 \mathrm{wt} \%$

As an important aim of the present work is to develop films that can release chitosan in a controlled way, the release of chitosan was studied for different chitosan/cellulose ratios in the films, taking account of the time dependence of the release over a wide $\mathrm{pH}$ range. Studies of the weight loss of the films were complemented by FT-IR investigations to characterize the nature of the released material. An interesting question is to what extent entanglement between the different polysaccharide molecules and co-crystallization affect the release.

The measurements of chitosan release were performed by immersing the nanocomposite samples in the aqueous solutions with $\mathrm{pH}$ of 3,5 and 7 . The dry weight of the swollen samples was recorded after 1, 3, 6, 9 and $12 \mathrm{~h}$. As mentioned above, the swelling ratios reached equilibrium after the first $12 \mathrm{~h}$, therefore the weight loss within the first $12 \mathrm{~h}$ was monitored.

Table 2 Comparison of chitosan contents of the residues of C75 after $12 \mathrm{~h}$ swelling test

\begin{tabular}{lll}
\hline & \multicolumn{2}{l}{ Chitosan content, wt\% } \\
\cline { 2 - 3 } & $\mathrm{pH} \mathrm{3}$ & $\mathrm{pH} \mathrm{5}$ \\
\hline Determined via FT-IR & 47 & 52 \\
Estimated from weight loss & 44 & 54 \\
\hline
\end{tabular}

(b)

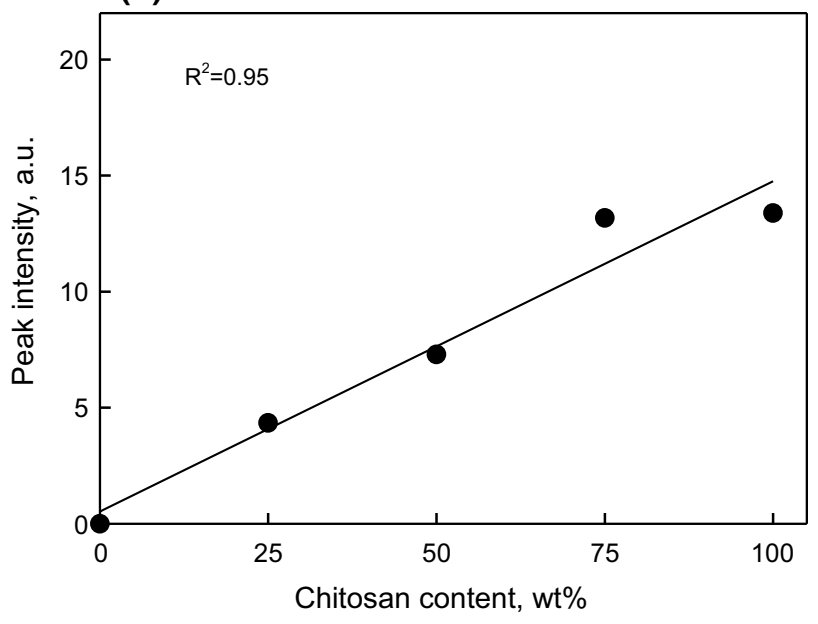

chitosan; (d) C75, with 25 wt $\%$ cellulose and 75 wt $\%$ chitosan, and (e) $100 \mathrm{wt} \%$ regenerated chitosan. Spectra (b), (c), (d) and (e) show the characteristic bands of the amide groups at $1646 \mathrm{~cm}^{-1}$ and $1570 \mathrm{~cm}^{-1}$

Table 1 shows the weight loss of the prepared samples after $12 \mathrm{~h}$ at $\mathrm{pH} 3,5$ and 7 ; this indicates that chitosan was released into the testing medium. The nanocomposite samples with higher chitosan content lost more weight; this agrees with the swelling ratios and thickness changes of the samples, with higher chitosan contents at low $\mathrm{pH}$ leading to increased osmotic pressure and chitosan protonation. The highest weight loss, 55\%, occurred with $\mathrm{C} 75$ at $\mathrm{pH} 3$. However, the C75 was not disintegrated, which is most probably due to physical entanglement and interlocking by the insoluble cellulose polymer chains. The lower weight loss in $\mathrm{C} 75$ at $\mathrm{pH} 5$ than at $\mathrm{pH} 3$ was mostly due to the lower degree of protonation of chitosan. Comparing C25 with $\mathrm{C} 75$, the former sample lost much less weight and had smaller porous structures. The lower the chitosan content of the nanocomposite, the lower the osmotic pressure, leading to less swelling and less chitosan release. The data in Table 1 apparently indicate that the cellulose molecules in the composite matrix strongly decreased the release of chitosan.

The weight loss at $\mathrm{pH} 7$ is dramatically lower than at the lower $\mathrm{pH}$ values investigated, consistent with a low degree of protonation. Again comparing this with the pure chitosan, which has a weight loss of $10 \mathrm{wt} \%$ at $\mathrm{pH} 7$, we infer a very important effect of the mixing with cellulose in the films. 


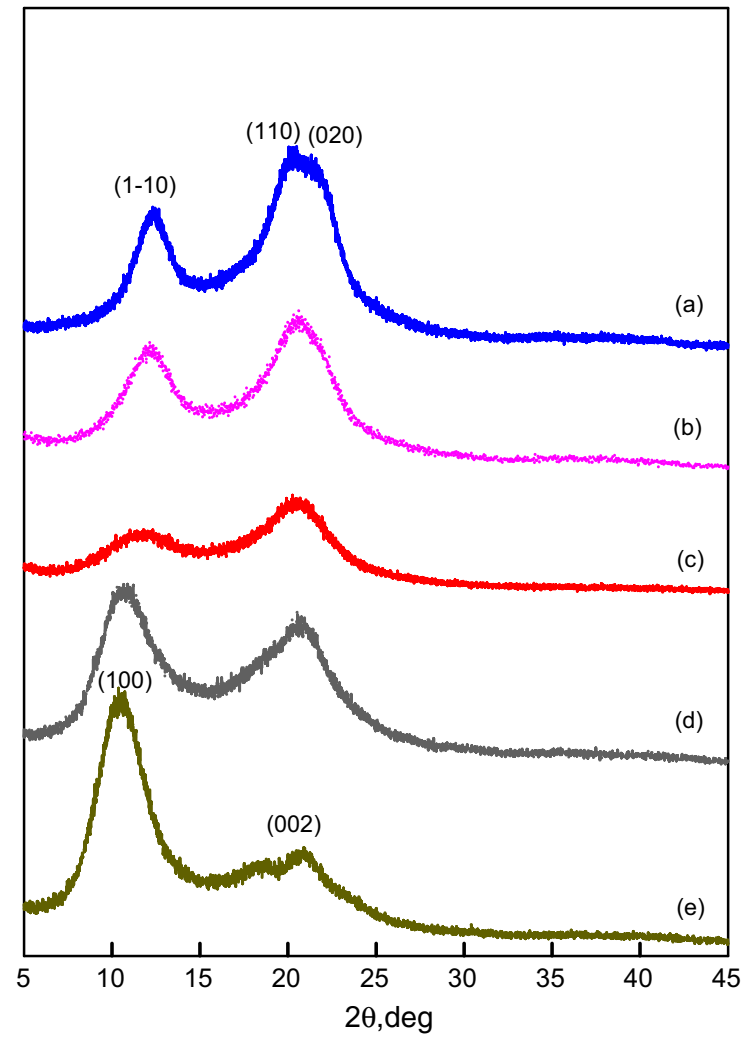

Fig. 5 X-ray diffraction profiles of the regenerated cellulose (a), three co-regenerated nanocomposite samples, C25, C50 and C75, i.e., (b), (c), and (d), and the regenerated chitosan (e). Both the regenerated cellulose and chitosan display characteristic diffraction peaks. The nanocomposite samples display weaker diffraction peak intensities, indicating that the nanocomposite samples are more amorphous

For the $75 \%$ chitosan films, the weight loss was monitored as a function of time at $\mathrm{pH} 3$ and 5 . Important features of the data reported in Fig. 3 are that there is an initial lag period before the release speeds up and that the release slows with time. Since protonation can be assumed to be fast, we attribute the initial slow release to slow chain disentanglement. We note that not all chitosan was released even after a relatively long time, attributing this to the entanglement and co-crystallization effects. Lowering the $\mathrm{pH}$ from 5 to 3 had a minor effect, explainable by a high degree of protonation even at the higher $\mathrm{pH}$.

FT-IR identifies the amide functional groups in the samples and enables quantitative analysis of the chitosan content. Figure 4A shows the spectra identifying chitosan in the samples. Within the $1900-500 \mathrm{~cm}^{-1}$ spectral window, the characteristic absorption bands of chitosan were observed, including the $\mathrm{C}=\mathrm{O}$ stretching from amide $\mathrm{I}$ at $1646 \mathrm{~cm}^{-1}$ and $\mathrm{N}-$ $\mathrm{H}$ bending from amide II at $1570 \mathrm{~cm}^{-1}$ (Sowjanya et al. 2013). The band at approximately $1637 \mathrm{~cm}^{-1}$ represents the bending mode of the adsorbed water $(\mathrm{Li}$ et al. 2010). Compared with the spectrum of the cellulose sample, the absorption of the $-\mathrm{NH}$ bending increased when the nanocomposites contained more chitosan.

Figure 4B shows a regression analysis based on the FT-IR spectra in Fig. 4A. The absorption peak intensity of amide II at $1570 \mathrm{~cm}^{-1}$ is normalized according to the intensities of the common peaks at $1020 \mathrm{~cm}^{-1}$ and $1900 \mathrm{~cm}^{-1}$ (Wibowo et al. 2005). The analysis finds a reliable linear regression with a coefficient of determination of 0.95 , indicating that the chitosan content is correlated to the amide II absorption peak intensity from chitosan. The residues from $\mathrm{C} 75$ at $\mathrm{pH} 3$ and 5 after $12 \mathrm{~h}$ were dried and scanned with FT-IR and the chitosan content was back-calculated from the linear regression. The chitosan contents of the C75 residues were also calculated from the weight loss after $12 \mathrm{~h}$, assuming that the cellulose was not dissolved during the tests. Table 2 shows that the chitosan contents calculated from FT-IR quantification deviated slightly from the ones estimated from weight loss at both $\mathrm{pH} 3$ and 5, implying that the FT-IR is a feasible method for quantification purposes and can provide reliable results. The deviation is within the statistical margin of error.

\section{Co-crystallization of cellulose and chitosan}

Since the co-crystallization of cellulose and chitosan would affect the structural features of the nanocomposite films, we studied the crystallinity using X-ray diffraction (XRD). The XRD patterns of the regenerated cellulose, regenerated chitosan and the nanocomposite films are shown in Fig. 5. The regenerated cellulose exhibits cellulose II peaks at $2 \theta$ of $12.2^{\circ}$ and $20.3^{\circ}$, which represent the crystallites with Miller indices of (1-10) and a combination of (110) and (020) at $2 \theta$ of $19.9^{\circ}$ and $21.9^{\circ}$, respectively (French and Santiago Cintrón 2013; French 2014). The overlapping of the two peaks could possibly originate from the formation of smaller cellulose crystallites and fewer ordered domains in the regenerated cellulose II. The regenerated chitosan sample exhibits main diffraction peaks of (100) and (002) at $2 \theta$ of $10.4^{\circ}$ and $20.8^{\circ}$, 


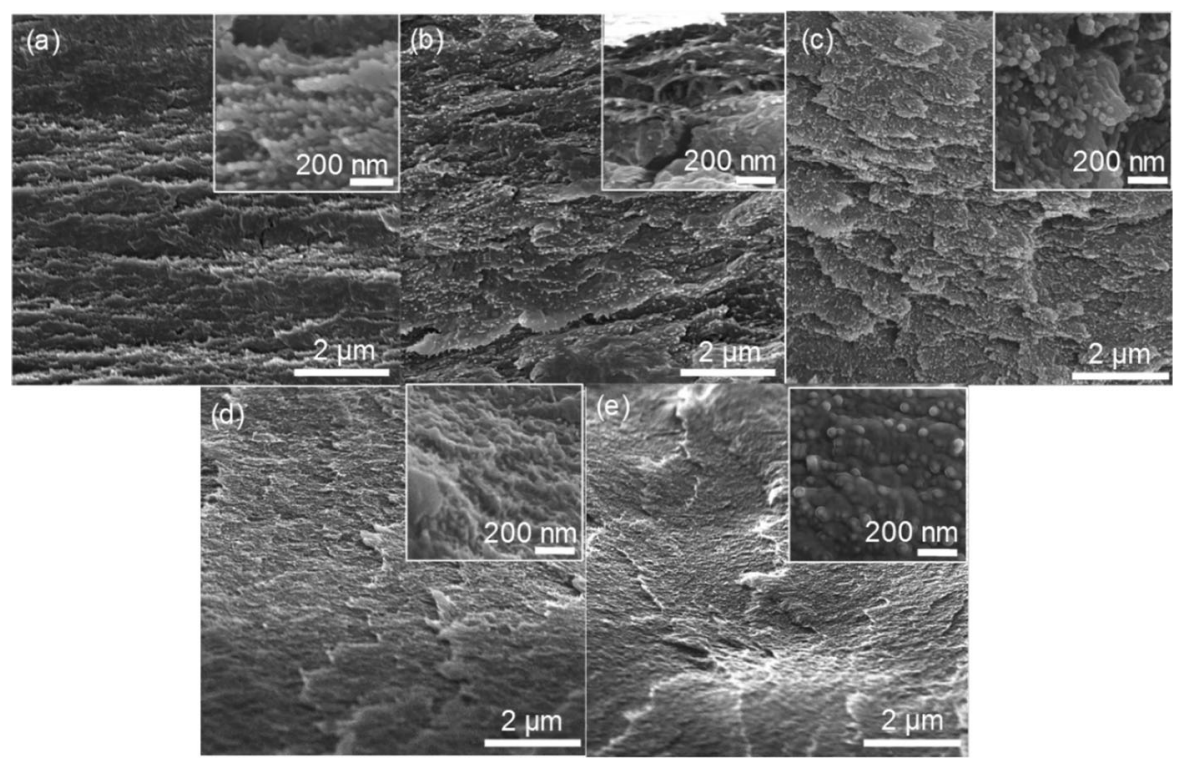

Fig. 6 SEM images of the fractured cross-section of the nanocomposite films at different magnifications: a regenerated cellulose with a parallel-lamellar structure and 20-nm-wide nanofibrils; b C25, with 75 wt $\%$ cellulose and 25 wt $\%$ chitosan; c C50, with 50 wt $\%$ cellulose and 50 wt $\%$ chitosan; and d C75,

respectively (Clark and Smith 1935; Sakurai et al. 1985). The XRD patterns of the C25, C50, and C75 samples, which represent the co-regeneration of the nanocomposites with different cellulose-chitosan mixing ratios, show diffraction patterns similar to those of cellulose or chitosan but with different intensities and slightly shifted diffraction angles.

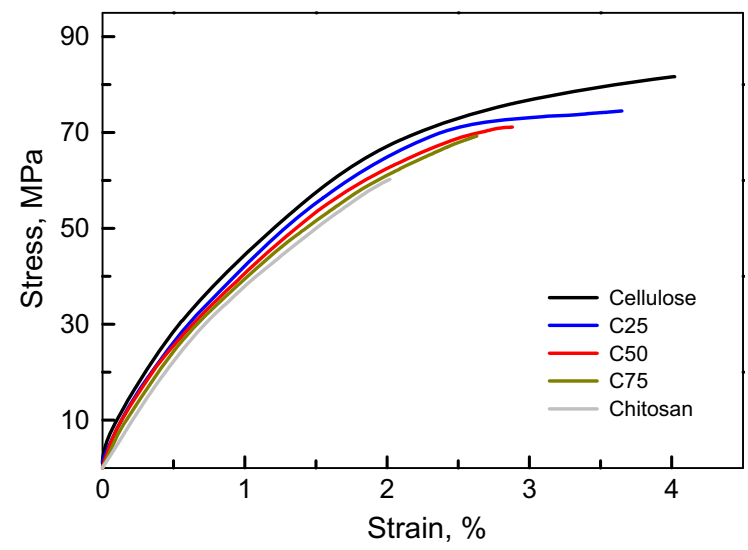

Fig. 7 The uniaxial tensile stress-strain curves of pure cellulose, C25, C50, C75 and pure chitosan. The pure cellulose film displays the best stress-strain properties. Increased additions of chitosan slightly worsen the stress-strain properties of the nanocomposite samples with $25 \mathrm{wt} \%$ cellulose and $75 \mathrm{wt} \%$ chitosan. All three films displayed less aligned and loosely packed microstructures, while e shows the tightly packed microstructure of regenerated chitosan

Compared with the pattern of cellulose alone, the diffraction peaks for nanocomposite samples $\mathrm{C} 25$ and C50 are of clearly lower intensity and broader peaks are obesrved at both $12.2^{\circ}$ and $20.3^{\circ} 2 \theta$. These results indicate that adding chitosan to the nanocomposite not only hindered the normal crystallization of cellulose into cellulose II, but also decreased the crystallites size and interfered with the preferred orientation of the crystallites in the composite films (Hasegawa et al. 1992; Nam et al. 2016). In the C50 nanocomposite, this observation is more pronounced, and the intensities of the diffraction peaks in C50 are the lowest among the samples. This suggests that the mixing cellulose and chitosan would interfere with the crystallization and result in a more amorphous nanocomposite with smaller crystallites (Nam et al. 2016).

Similarly, adding cellulose to chitosan does not favor the crystallization of chitosan. The C75 sample, containing $25 \mathrm{wt} \%$ cellulose, clearly displays a decreased diffraction peak intensity at $2 \theta$ of $10.4^{\circ}$ and $20.8^{\circ}$ compared with that of the $100 \mathrm{wt} \%$ chitosan film. This is attributed to the interferences from the cocrystallization of cellulose and chitosan, which render 
Table 3 Mechanical properties of cellulose, chitosan and the nanocomposite films

\begin{tabular}{lllll}
\hline Sample & $\begin{array}{l}\text { Tensile stress } \\
(\mathrm{MPa})\end{array}$ & $\begin{array}{l}\text { Tensile strain } \\
(\%)\end{array}$ & $\begin{array}{l}\text { Elastic modulus } \\
(\mathrm{GPa})\end{array}$ & $\begin{array}{l}\text { Density } \\
\left(\mathrm{kg} \mathrm{m}^{-3}\right)\end{array}$ \\
\hline Cellulose & $82 \pm 4.8$ & $4.0 \pm 0.7$ & $6.6 \pm 0.4$ & $1520 \pm 30$ \\
C25 & $74 \pm 5.0$ & $3.6 \pm 0.5$ & $6.0 \pm 0.4$ & $1480 \pm 20$ \\
C50 & $71 \pm 3.5$ & $2.8 \pm 0.5$ & $5.6 \pm 0.3$ & $1420 \pm 40$ \\
C75 & $69 \pm 6.7$ & $2.6 \pm 0.4$ & $5.2 \pm 0.3$ & $1400 \pm 30$ \\
Chitosan & $60 \pm 5.9$ & $2.0 \pm 0.4$ & $4.7 \pm 0.4$ & $1350 \pm 20$ \\
\hline
\end{tabular}

a less ordered structure in the composite (Hasegawa et al. 1992).

Morphology of the cellulose-chitosan nanocomposite films

As discussed above, different $\mathrm{pH}$ responses and diffraction patterns were exhibited by the nanocomposites as the cellulose-chitosan mixing ratio was varied. It was deemed of interest to correlate these findings with the morphologies of the different films. Figure 6 shows the cross-sections of the fractured films. Figure 6 a shows that the regenerated cellulose film has a parallel lamella-like structure. The micrograph further shows that nanofibrils, approximately $20 \mathrm{~nm}$ in cross-section, are aligned in a thin layer and stacked into a lamellar form. Others have also verified similar structural features in regenerated cellulose (Chen et al. 2007; Duchemin et al. 2009). Both XRD and molecular dynamic simulations have confirmed that cellulose regeneration begins with the hydrophobic stacking of cellulose molecules into molecular sheets and is followed by progressive bonding via hydrogen bonds (Cousins and Brown 1995; Miyamoto et al. 2009). Compared with pure cellulose, the nanocomposite samples in Fig. 6b-d clearly display lower-order microstructures, i.e., less aligned and more loosely packed. This correlates well with the changes in crystallinity deduced from XRD diffraction peaks. During the association of cellulosic lamellae, chitosan may move between the lamellae to render a less ordered structure (Hasegawa et al. 1992). In the nanocomposite samples, nanofibrils approximately $20 \mathrm{~nm}$ in cross-section were also observed. Furthermore, the morphology appearing in the fractured cross-section of the regenerated chitosan in Fig. 6e indicates tightly packed microstructures aligned in the domains. Based on the observed changes in the microstructures discussed above, we suggest an explanation for the weakened diffraction intensities in the XRD analysis.

Mechanical properties of the cellulose-chitosan nanocomposite films

Uniaxial tensile stress-strain tests were performed on the different samples to determine their mechanical properties. Figure 7 shows the tensile stress-strain curves of cellulose, chitosan, and nanocomposite films, while the results of the tensile testing are presented in Table 3. The $100 \mathrm{wt} \%$ cellulose film exhibited the best stress-strain properties, with tensile stress and strain values of $82 \mathrm{MPa}$ and $4.0 \%$, respectively. As listed in Table 3, the cellulose film had the highest density, $1520 \mathrm{~kg} \mathrm{~m}^{-3}$, of the tested samples, indicating that there were stronger intermolecular interactions between the polymer chains in pure cellulose than in the prepared nanocomposites. Furthermore, the cellulose film also displayed better aligned microstructures than did the cellulose-chitosan nanocomposites, as discussed in the previous section. This implies that its densely packed and aligned microstructure contributes to the higher tensile stress-strain performance of the pure cellulose film.

Compared with the pure cellulose film, the tensile stress and strain of the nanocomposite films decreased as more chitosan was incorporated. Table 3 presents the density and tensile stress-strain properties at different chitosan ratios in the nanocomposites: the densities dropped from $1480 \mathrm{~kg} \mathrm{~m}^{-3}$ in $\mathrm{C} 25$ to $1400 \mathrm{~kg} \mathrm{~m}^{-3}$ in $\mathrm{C} 75$, while the tensile stress and strain decreased from $74 \mathrm{MPa}$ and 3.6\%, respectively, in $\mathrm{C} 25$, to $69 \mathrm{MPa}$ and $2.6 \%$ in $\mathrm{C} 75$. The elastic modulus of the nanocomposite films also decreased, from 6.0 GPa in $\mathrm{C} 25$ to $5.2 \mathrm{GPa}$ in $\mathrm{C} 75$. These results agree with the observations from the XRD and SEM analyses and suggest that increased chitosan content leads to a less aligned and more loosely packed 
microstructure in the nanocomposite, resulting in nanocomposite samples with worsened mechanical properties. Other studies have confirmed that increased chitosan content decreases the domain size of cellulose, inducing lower mechanical strength in composite films (Hasegawa et al. 1992).

The $100 \mathrm{wt} \%$ chitosan film had inferior tensile stress-strain properties, agreeing with the results of other investigations (Butler et al. 1996). The tensile stress and strain of the chitosan film were $60 \mathrm{MPa}$ and $2.0 \%$, respectively. In the present work, the chitosan used to make the nanocomposite films had a DD of $89 \%$. The remaining amide groups from the chitin affect the brittleness of the film sample, impairing its tensile stress-strain properties (Nunthanid et al. 2001).

\section{Conclusions}

In this work, cellulose-chitosan nanocomposite films with tunable $\mathrm{pH}$ response and slow release of chitosan were successfully prepared. The nanocomposite films displayed high swelling at $\mathrm{pH} 3$ and 5, due to the osmotic effects of the difference in mobile counterion concentration between the gel and solution phases, as described by Gibbs-Donnan theory. Adjusting the chitosan content of the nanocomposites allowed the $\mathrm{pH}$ response of the film and the slow release of chitosan at different $\mathrm{pH}$ values to be tuned. The FT-IR quantification determined chitosan residues after slow release agrees with the estimated values derived from the weight loss of the nanocomposite film. The $\mathrm{pH}-$ responsive nanocomposite films exhibited finely assembled microstructures, which other studies have attributed to hydrophobic interactions. The FE-SEM study verified that the addition of chitosan disrupted the fine structure of the parallel lamellae, worsening the mechanical performance of the nanocomposite samples. These pH-responsive cellulose-chitosan nanocomposite films are non-toxic, biocompatible, biodegradable, and offer an alternative for constructing cellulose-chitosan nanocomposites with slowrelease characteristics.

Acknowledgments SCA R\&D Centre and Bo Westerlind are acknowledged for MTS testing assistance. This work was supported by the Swedish Research Council FORMAS [Grant No. 942-2015-251] and Interreg Sverige-Norge [Grant No. 20201315].

\section{Compliance with ethical standards}

Conflict of interest The authors declare that they have no conflict of interest.

Open Access This article is distributed under the terms of the Creative Commons Attribution 4.0 International License (http:// creativecommons.org/licenses/by/4.0/), which permits unrestricted use, distribution, and reproduction in any medium, provided you give appropriate credit to the original author(s) and the source, provide a link to the Creative Commons license, and indicate if changes were made.

\section{References}

Alexandridis P, Ghasemi M, Furlani EP, Tsianou M (2018) Solvent processing of cellulose for effective bioresource utilization. Curr Opin Green Sustain Chem 14:40-52. https://doi.org/10.1016/j.cogsc.2018.05.008

Alves L, Medronho B, Antunes FE, Topgaard D, Lindman B (2016) Dissolution state of cellulose in aqueous systems. 1. Alkaline Solv Cellul 23:247-258. https://doi.org/10.1007/ s10570-015-0809-6

Bialik E et al (2016) Ionization of cellobiose in aqueous alkali and the mechanism of cellulose dissolution. J Phys Chem Lett. https://doi.org/10.1021/acs.jpclett.6b02346

Bolton GR, Boesch AW, Basha J, LaCasse DP, Kelley BD, Acharya H (2011) Effect of protein and solution properties on the donnan effect during the ultrafiltration of proteins. Biotechnol Progr 27:140-152. https://doi.org/10.1002/ btpr.523

Butler BL, Vergano PJ, Testin RF, Bunn JM, Wiles JL (1996) Mechanical and barrier properties of edible chitosan films as affected by composition and storage. J Food Sci 61:953-956. https://doi.org/10.1111/j.1365-2621.1996. tb10909.x

Cai J, Zhang L (2005) Rapid dissolution of cellulose in LiOH/ urea and $\mathrm{NaOH} /$ urea aqueous solutions. Macromol Biosci 5:539-548. https://doi.org/10.1002/mabi.200400222

Chen X et al (2007) Structure study of cellulose fibers wet-spun from environmentally friendly $\mathrm{NaOH} /$ urea aqueous solutions. Biomacromol 8:1918-1926. https://doi.org/10.1021/ bm061186i

Clark GL, Smith AF (1935) X-ray diffraction studies of chitin, chitosan, and derivatives. J Phys Chem 40:863-879. https://doi.org/10.1021/j150376a001

Cousins SK, Brown RM Jr (1995) Cellulose I microfibril assembly: computational molecular mechanics energy analysis favours bonding by van der Waals forces as the initial step in crystallization. Polymer 36:3885-3888. https://doi.org/10.1016/0032-3861(95)99782-P

Duan J, Liang X, Cao Y, Wang S, Zhang L (2015) High strength chitosan hydrogels with biocompatibility via new avenue based on constructing nanofibrous architecture. Macromolecules 48:2706-2714. https://doi.org/10.1021/acs. macromol.5b00117

Duan J, Liang X, Zhu K, Guo J, Zhang L (2017) Bilayer hydrogel actuators with tight interfacial adhesion fully 
constructed from natural polysaccharides. Soft Matter 13:345-354. https://doi.org/10.1039/c6sm02089e

Duchemin BJC, Newman RH, Staiger MP (2009) Structureproperty relationship of all-cellulose composites. Compos Sci Technol 69:1225-1230. https://doi.org/10.1016/j. compscitech.2009.02.027

Fang Y, Zhang R, Duan B, Liu M, Lu A, Zhang L (2017) Recyclable universal solvents for chitin to chitosan with various degrees of acetylation and construction of robust hydrogels. ACS Sustain Chem Eng 5:2725-2733. https:// doi.org/10.1021/acssuschemeng.6b03055

Fernandes SCM, Freire CSR, Silvestre AJD, Neto CP, Gandini A (2011) Novel materials based on chitosan and cellulose. Polym Int 60:875-882. https://doi.org/10.1002/pi.3024

French AD (2014) Idealized powder diffraction patterns for cellulose polymorphs. Cellulose 21:885-896. https://doi. org/10.1007/s10570-013-0030-4

French A, Santiago Cintrón M (2013) Cellulose polymorphy, crystallite size, and the Segal crystallinity index. Cellulose 20:583-588. https://doi.org/10.1007/s10570-012-9833-y

Glasser W et al (2012) About the structure of cellulose: debating the Lindman hypothesis. Cellulose 19:589-598. https:// doi.org/10.1007/s10570-012-9691-7

Grignon J, Scallan AM (1980) Effect of pH and neutral salts upon the swelling of cellulose gels. J Appl Polym Sci 25:2829-2843. 070251215

Hadwiger LA (2013) Multiple effects of chitosan on plant systems: solid science or hype. Plant Sci 208:42-49. https:// doi.org/10.1016/j.plantsci.2013.03.007

Hasegawa M, Isogai A, Onabe F, Usuda M, Atalla RH (1992) Characterization of cellulose-chitosan blend films. J Appl Polym Sci 45:1873-1879. https://doi.org/10.1002/app. 1992.070451101

Isogai A (1997) NMR analysis of cellulose dissolved in aqueous $\mathrm{NaOH}$ solutions. Cellulose 4:99-107. https://doi.org/10. 1023/A:1018471419692

Kim J, Cai Z, Lee HS, Choi GS, Lee DH, Jo C (2011) Preparation and characterization of a bacterial cellulose/chitosan composite for potential biomedical application. J Polym Res 18:739-744. https://doi.org/10.1007/s10965-0109470-9

Klemm D, Heublein B, Fink HP, Bohn A (2005) Cellulose: fascinating biopolymer and sustainable raw material. Angew Chem Int Ed 44:3358-3393. https://doi.org/10. 1002/anie.200460587

Kuzmina O, Heinze T, Wawro D (2012) Blending of cellulose and chitosan in alkyl imidazolium ionic liquids isrn polymer. Science 2012:1-9. https://doi.org/10.5402/2012/ 251950

Li Q, Zhou JP, Zhang LN (2009) Structure and properties of the nanocomposite films of chitosan reinforced with cellulose whiskers. J Polym Sci Part B Polym Phys 47:1069-1077. https://doi.org/10.1002/polb.21711

Li S-M, Jia N, Zhu J-F, Ma M-G, Sun R-C (2010) Synthesis of cellulose-calcium silicate nanocomposites in ethanol/water mixed solvents and their characterization. Carbohydr Polym 80:270-275. https://doi.org/10.1016/j.carbpol. 2009.11.024

Li Y, Wang J, Liu X, Zhang S (2018) Towards a molecular understanding of cellulose dissolution in ionic liquids: anion/cation effect, synergistic mechanism and physicochemical aspects. Chem Sci 9:4027-4043. https://doi.org/ $10.1039 / \mathrm{c} 7 \mathrm{sc} 05392 \mathrm{~d}$

Liebert T (2010) Cellulose solvents—remarkable history, bright future. In: Liebert T (ed) Cellulose solvents: for analysis, shaping and chemical modification, vol 1033. ACS symposium series. American Chemical Society, Washington, pp 3-54. https://doi.org/10.1021/bk-2010-1033.ch001

Lindman B, Karlström G, Stigsson L (2010) On the mechanism of dissolution of cellulose. J Mol Liq 156:76-81. https:// doi.org/10.1016/j.molliq.2010.04.016

Lindman B, Medronho B, Alves L, Costa C, Edlund H, Norgren M (2017) The relevance of cellulose structural features and interactions on dissolution, regeneration, gelation and plasticization phenomena. PCCP. https://doi.org/10.1039/ c7cp02409f

Liu $\mathrm{H}$ et al (2018) A functional chitosan-based hydrogel as a wound dressing and drug delivery system in the treatment of wound healing. RSC Adv 8:7533-7549. https://doi.org/ $10.1039 / \mathrm{c} 7 \mathrm{ra} 13510 \mathrm{f}$

Medronho B, Lindman B (2014) Competing forces during cellulose dissolution: From solvents to mechanisms. Curr Opin Colloid Interface Sci 19:32-40. https://doi.org/10. 1016/j.cocis.2013.12.001

Miyamoto H, Umemura M, Aoyagi T, Yamane C, Ueda K, Takahashi K (2009) Structural reorganization of molecular sheets derived from cellulose II by molecular dynamics simulations. Carbohydr Res 344:1085-1094. https://doi. org/10.1016/j.carres.2009.03.014

Nam S, French AD, Condon BD, Concha M (2016) Segal crystallinity index revisited by the simulation of X-ray diffraction patterns of cotton cellulose I $\beta$ and cellulose II. Carbohydr Polym 135:1-9. https://doi.org/10.1016/j. carbpol.2015.08.035

Nguyen TTB, Hein S, Ng CH, Stevens WF (2008) Molecular stability of chitosan in acid solutions stored at various conditions. J Appl Polym Sci 107:2588-2593. https://doi. org/10.1002/app.27376

Niroomand F, Khosravani A, Younesi H (2016) Fabrication and properties of cellulose-nanochitosan biocomposite film using ionic liquid. Cellulose 23:1311-1324. https://doi. org/10.1007/s10570-016-0872-7

Nunthanid J, Puttipipatkhachorn S, Yamamoto K, Peck GE (2001) Physical properties and molecular behavior of chitosan films. Drug Dev Ind Pharm 27:143-157. https://doi. org/10.1081/DDC-100000481

Omidi M, Yadegari A, Tayebi L (2017) Wound dressing application of $\mathrm{pH}$-sensitive carbon dots/chitosan hydrogel. RSC Adv 7:10638-10649. https://doi.org/10.1039/ c6ra25340g

Pinkert A, Marsh KN, Pang S, Staiger MP (2009) Ionic liquids and their interaction with cellulose. Chem Rev 109:6712-6728. https://doi.org/10.1021/cr9001947

Qiu X, Hu S (2013) "Smart" materials based on cellulose: a review of the preparations properties, and applications. Materials 6:738-781. https://doi.org/10.3390/ma6030738

Sakurai K, Shibano T, Kimura K, Takahashi T (1985) Crystal structure of chitosan II. Molecular packing in unit cell of crystal. Sen'i Gakkaishi 41:T361-T368. https://doi.org/10. 2115/fiber.41.9_T361 
Saric SP, Schofield RK (1946) The dissociation constants of the carboxyl and hydroxyl groups in some insoluble and solforming polysaccharides. Proc R Soc Lond Ser Math Phys Sci 185:431-447. https://doi.org/10.1098/rspa.1946.0029

Sidorenko A, Krupenkin T, Taylor A, Fratzl P, Aizenberg J (2007) Reversible switching of hydrogel-actuated nanostructures into complex micropatterns. Science 315:487-490. https://doi.org/10.1126/science.1135516

Sowjanya JA, Singh J, Mohita T, Sarvanan S, Moorthi A, Srinivasan N, Selvamurugan N (2013) Biocomposite scaffolds containing chitosan/alginate/nano-silica for bone tissue engineering. Colloids Surf B Biointerfaces 109:294-300. https://doi.org/10.1016/j.colsurfb.2013.04. 006

Srinivasan K, Mahadevan R (2010) Characterization of proton production and consumption associated with microbial metabolism. BMC Biotechnol 10:2-12. https://doi.org/10. 1186/1472-6750-10-2

Swatloski RP, Spear SK, Holbrey JD, Rogers RD (2002) Dissolution of cellose with ionic liquids. J Am Chem Soc 124:4974-4975. https://doi.org/10.1021/ja025790m

Szymanska E, Winnicka K (2015) Stability of chitosan-a challenge for pharmaceutical and biomedical applications. Mar Drugs 13:1819-1846. https://doi.org/10.3390/ md13041819

Tang XZ, Alavi S (2011) Recent advances in starch, polyvinyl alcohol based polymer blends, nanocomposites and their biodegradability. Carbohydr Polym 85:7-16. https://doi. org/10.1016/j.carbpol.2011.01.030

Wang QZ, Chen XG, Liu N, Wang SX, Liu CS, Meng XH, Liu CG (2006) Protonation constants of chitosan with different molecular weight and degree of deacetylation. Carbohydr
Polym 65:194-201. https://doi.org/10.1016/j.carbpol. 2006.01.001

Wibowo S, Velazquez G, Savant V, Torres JA (2005) Surimi wash water treatment for protein recovery: effect of chitosan-alginate complex concentration and treatment time on protein adsorption. Bioresour Technol 96:665-671. https://doi.org/10.1016/j.biortech.2004.06.024

Xiao W et al (2013) Preparation, structure, and properties of chitosan/cellulose/multiwalled carbon nanotube composite membranes and fibers. J Appl Polym Sci 128:1193-1199. https://doi.org/10.1002/app.38329

Yang J, Duan J, Zhang L, Lindman B, Edlund H, Norgren M (2016) Spherical nanocomposite particles prepared from mixed cellulose-chitosan solutions. Cellulose 23:3105-3115. https://doi.org/10.1007/s10570-016-10294

Zargar V, Asghari M, Dashti A (2015) A review on chitin and chitosan polymers: structure chemistry, solubility, derivatives, and applications. ChemBioEng Reviews 2:204-226. https://doi.org/10.1002/cben.201400025

Zhang W, Xia W (2014) Dissolution and stability of chitosan in a sodium hydroxide/urea aqueous solution. J Appl Polym Sci 131:39819-39825. https://doi.org/10.1002/app.39819

Zhang YH, Cui J, Lynd LR, Kuang LR (2006) A transition from cellulose swelling to cellulose dissolution by o-phosphoric acid: evidence from enzymatic hydrolysis and supramolecular structure. Biomacromol 7:644-648. https://doi.org/10.1021/bm050799c

Publisher's Note Springer Nature remains neutral with regard to jurisdictional claims in published maps and institutional affiliations. 